\title{
A Study on Clinical and Pathological Responses to Neoadjuvant Chemotherapy in Breast Carcinoma
}

This article was published in the following Dove Press journal:

Breast Cancer: Targets and Therapy

\author{
Supreeth Kumar Reddy \\ Kunnuru' \\ Manuneethimaran \\ Thiyagarajan (D) \\ Jovita Martin Daniel ${ }^{2}$ \\ Balaji Singh K $\mathbb{D}^{\prime}$
}

'General Surgery Department, Sri Ramachandra Medical University, Chennai 600II6, India; ${ }^{2}$ Medical

Oncology Department, Sri Ramachandra Medical University, Chennai 600116, India

Correspondence: Manuneethimaran Thiyagarajan

General Surgery Department, Sri

Ramachandra Medical University, 9036,

Tower 9b, Prestige, lyyapanthanagal,

Chennai 614613, India

Tel +919952044955

Email profmaran@gmail.com

Jovita Martin Daniel

Medical Oncology Department, Sri

Ramachandra Medical University, Porur,

Chennai 600116, India Porur

Email jovimartin4@gmail.com

\begin{abstract}
Aim and objectives: To assess the effectiveness of neo-adjuvant chemotherapy and its impact on the clinical and pathological response in locally advanced breast cancer. To compare molecular subtypes of breast cancer with response to neo-adjuvant chemotherapy.

Patients and methods: This was a prospective study on patients who received neoadjuvant chemotherapy for breast carcinoma for a 3-year period. A total of 60 patients who presented with locally advanced breast cancer (LABC) were treated with neoadjuvant chemotherapy. Forty patients were treated with the 5-fluorouracil, epirubicin, and cyclophosphamide (FEC) schedule, 16 patients were treated with Adriamycin and cyclophosphamide (AC), and four patients were treated with oral cyclophosphamide, intravenous methotrexate, and fluorouracil (CMF). Taxol was added in all node-positive cases, triple negative breast cancer (TNBC), and Her 2 positive cases. The clinical response was assessed with RECIST criteria after neoadjuvant chemotherapy. The response was compared with molecular subtypes of carcinoma breast and receptor status individually.
\end{abstract}

Results: A total of 60 female patients receiving primary chemotherapy for locally advanced breast malignancy were studied. The median age of the patients at the time of diagnosis was 44 years (range $=24-73)$. In terms of menopausal status, $25(42 \%)$ patients were pre-menopausal and $35(58 \%)$ patients were post-menopausal. Histological classification showed invasive ductal carcinoma in $72 \%$ of patients, invasive lobular carcinoma in $15 \%$ of patients, and other types including mixed patterns in $13 \%$ of patients. Among 60 patients, 16 patients $(26.6 \%)$ had clinically complete remission (cCR), 30 patients $(50 \%)$ had partial remission, eight patients (13.3\%) had stable disease, and six patients (10\%) had progressive disease. Following neoadjuvant chemotherapy, 46 (76.6\%) patient underwent Modified radical mastectomy surgery. Target therapy was given for Her2 neu patients after surgery. Hormonal therapy was added to hormone ER PR positive cases postoperatively. Eight patients (13.3\%) among this operated cases attained complete pathological response. Conclusion: Preoperative chemotherapy downstages the primary tumors and axillary metastasis in patients with locally advanced breast carcinoma. Comparison of molecular subtypes with chemotherapy response is a better way to find out the predictors of response to chemotherapy.

Keywords: neoadjuvant chemotherapy, carcinoma breast, predictors of NACT response, clinical and pathological response to NACT

\section{Introduction}

Worldwide, locally advanced breast carcinoma is a significant problem. Bulky primary tumor of the chest wall with or without axillary lymph nodes is defined as locally advanced malignancy (involvement of axillary and/or internal mammary nodes with matting). ${ }^{1}$ In metastatic disease limited to supra clavicular nodes, 
survival increased by multi-modality mode of treatment. ${ }^{2}$ After this isolated supraclavicular metastasis was included in the stage III/LABC category. ${ }^{3}$ However, in spite of radical surgery there is reduced long-term survival due to the high incidence of loco-regional recurrences. ${ }^{4}$ In locally advanced breast carcinoma, neo-adjuvant systemic therapy (also called primary systemic therapy or induction therapy) has become a valuable strategy. But not all patients in this category respond well to Neo-adjuvant chemotherapy (NACT). Only in 30\% of patients does complete or partial response occur after neoadjuvant chemotherapy. If chemotherapy is given early for micro-metastasis, the disease can be controlled. ${ }^{5}$

Moreover, NACT prior to surgery can make inoperable tumor operable and increase the rate of breast conservative surgery. ${ }^{6}$

The overall survival is improved by NACT in women with LABC. The prognosis is better for early breast disease. It is better in axillary lymph node negative patients than axillary lymph node positive patients. ${ }^{7}$ There is poor survival in patients with a great number of axillary lymph nodes and higher nodal status. Patients with a larger size breast tumor have poorer survival than small tumor patients. $^{7,8}$ Valagussa et al $^{8}$ show 5 years survival was $65 \%$ in tumors less than $5 \mathrm{~cm}$. It also shows the survival rate of $36 \%$ and $16 \%$ in breast tumors of size $5-10 \mathrm{~cm}$ and more than $10 \mathrm{~cm}$, respectively.

In addition to this, there is equally comparable survival in patients treated with NACT and directly operable breast tumor patients. ${ }^{9,10}$ There are many studies which compared the response to NACT with receptor status, Her2 neu, and menopausal status. If we include molecular subtypes also in this comparison we can derive correct predictors for response to NACT.

\section{Aim and Objectives}

In our study the aim was to assess the effect of neoadjuvant chemotherapy and its impact on clinical and pathological responses.

To compare the patients characteristic, receptor status, and molecular subtypes of carcinoma breast with response to NACT.

\section{Patients and Methods}

This was a prospective study on patients who received neoadjuvant chemotherapy in carcinoma breast for a 3-year period in Sri Ramachandra medical university hospital in 2015. A total of 60 patients who presented with LABC were treated with NACT. In the TNM staging classification, LABC is represented by stage IIB (T2-N1; T3-N0), IIIA (T0-N2; T1/2-N2; T3-N1/2), stage IIIB (T4, N0-2) and stage IIIC disease (any T, N3). Early breast carcinoma (less than stage 2b), metastatic breast carcinoma, and those who missed follow-up or were not willing to be included were excluded.

The consent for study was obtained from all patients. A complete explanation of the study purpose and nature of study was given to the patients. The participants were assured that participation was voluntary and they could withdraw from the study at any stage. We assured that the data collected would be kept confidentially and would be used only for research purposes. Institutional Ethics committee approval was obtained.

The standard neoadjuvant treatment regimen of 5-fluorouracil, epirubicin, and cyclophosphamide (FEC) with two schedules was used: $500 \mathrm{mg} / \mathrm{m}^{2}$-fluorouracil, $75 \mathrm{mg} / \mathrm{m}^{2}$ epirubicin, and $500 \mathrm{mg} / \mathrm{m}^{2}$ cyclophosphamide or $600 \mathrm{mg} /$ $\mathrm{m}^{2}$ 5-fluorouracil, $60 \mathrm{mg} / \mathrm{m}^{2}$ epirubicin and $600 \mathrm{mg} / \mathrm{m}^{2}$ cyclophosphamide, both for six cycles on a 21-day cycle. Forty patients were treated with the FEC schedule. Other chemotherapy schedules used included AC (Adriamycin $60 \mathrm{mg} / \mathrm{m}^{2}$, cyclophosphamide $600 \mathrm{mg} / \mathrm{m}^{2}$ q21 for four cycles, 16 patients), CMF (oral cyclophosphamide $100 \mathrm{mg} / \mathrm{m}^{2}$ on days $1-14$ and intravenous methotrexate $40 \mathrm{mg} / \mathrm{m}^{2}$ and 5-fluorouracil $600 \mathrm{mg} / \mathrm{m}^{2}$ on days 1 and 8 , q28 for six cycles, for four patients). Paclitaxel was added $175 \mathrm{mg} / \mathrm{m}^{2}$ for a 3-week interval in node-positive cases.

Chemotherapy plan:

1. Triple negative/node positive with HER2 neu + cases received AC + Taxol (16 cases)

2. Node-negative with HER2 neu negative cases, received FEC regimen alone of six cycles (10 cases). Those patients with Her 2 Positive were treated (24 patients) with FEC x4 cycles NACT + Adjuvant Taxol $\mathrm{x} 4$ cycles. Among those who received Taxol in the adjuvant setting, eight patients received Taxol and Trastuzumab in the adjuvant setting. The overall number of patients who received FEC as NACT was 40 patients. ${ }^{11,12}$

3. Patients who did not tolerate anthracyclines, old, and frail patients with poor performance status received the CMF regimen (4 patients).

Baseline patient and tumor characteristics recorded included age, tumor stage, nodal stage, tumor grade, 
estrogen receptor (ER) status, progesterone receptor (PR) status, and HER2-neu. Clinical assessment and Sonomammogram were used to assess the tumor size and nodal status. Tru-cut biopsy was done for all patients. Histologic grade, immunohistochemistry (IHC) for estrogen/progesterone expression, HER2-neu expression via IHC or fluorescent in situ hybridization (FISH) was done for all patients. IHC analyses were performed on formalinfixed paraffin-embedded tissue sections. Positive ER and PR status was defined as at least $>1 \%$ of tumor cells with nuclear staining. Tumors were considered HER2 positive with a score of $3+$ on IHC and/or a FISH ratio of greater than 2.0. Clinical response was assessed after three cycles of chemotherapy and at the end of the treatment. According to RECIST criteria tumors, size and node size were measured after chemotherapy. RECIST 1.16 utilized the following classifications for therapeutic response: complete response (CR), primary tumor disappearance; partial response $(\mathrm{PR}), 30 \%$ or greater decrease in longest diameter of primary tumor; progressive disease (PD), 20\% or greater increase in longest diameter of primary tumor; stable disease (SD), tumors that did not show either sufficient shrinkage to be classified as PR or sufficient increase to be classified as PD.

Pathological response was assessed on completion of NACT and completion of surgery. The pCR was defined as having no residual invasive carcinoma in the breast and no tumor in the axillary lymph nodes. Patients with residual ductal carcinoma in-situ (DCIS) and no evidence of residual invasive disease were included in this category. ${ }^{13}$ The pCR rate was compared by clinical response category after three cycles of chemotherapy. All summary statistics were stated with 95\% confidence limits. SPSS version 17 was used to analyze statistical results. A $P$-value $<0.05$ was considered as a statistically significant value.

Breast cancer is broadly divided into distinct molecular subtypes (luminal A, luminal B, HER2, and triple negative) by gene expression profiling with prognostic significance. ${ }^{14}$

Our 60 cases were divided into four groups based on molecular sub-types:

1. Luminal A: Hormone positive and HER2 neu-

2. Luminal B: Hormone positive and Her2neu positive

3. Triple negative: Hormone negative and HER2 neu-

4. HER2: hormone negative and Her2neu positive

Comparison of clinical pathological response to chemotherapy was also performed with these sub-groups. All patients who responded to chemotherapy were operated on, and the rest of the patients (static and progressive patients) continued chemotherapy for another three cycles and were assessed. For paients with node positive, TNBC, and Her2 neu positive adjuvant Taxol was given. Target therapy was given for Her2 neu patients after surgery since our study was conducted with free medication side. Only for patients who could afford it was target therapy added after surgery. Hormonal therapy was added to hormone ER PR positive cases in the post-operative period. Post-operative radiotherapy was also given to all patients. Since not all patients were followed-up after therapy, exact 5-year survival rate could not be calculated.

\section{Results}

Sixty female patients receiving primary chemotherapy for locally advanced breast malignancy were studied. The median age of the patients at the time of diagnosis was 44 years (range $=24-73)$. In terms of menopausal status, $25(42 \%)$ patients were pre-menopausal and 35 (58\%) patients were post-menopausal . The mean tumor diameter measured clinically before starting chemotherapy was $9.2 \mathrm{~cm}$ (range=3$17 \mathrm{~cm})$. Axillary nodal status was N0 in eight patients $(13.3 \%), \mathrm{N} 1$ in 40 patients $(66.6 \%)$, and $\mathrm{N} 2$ in 12 patients $(20 \%)$.

A histological classification was done which showed invasive ductal carcinoma in $72 \%$ of patients, invasive lobular carcinoma in $15 \%$ of patients, and other types including mixed patterns in $13 \%$ of patients. Malignancy grading before starting chemotherapy, showed grade $(1+2)$ in $21(35 \%)$ patients and grade 3 with 39 $(65 \%)$ patients. Estrogen receptors showed positive results in 36 patients $(60 \%)$ and negative results in 24 patients (40\%). Progesterone receptors showed positive results in $31(51.6 \%)$ patients and negative results in $29(48.3 \%)$ patients. HER-2-neu receptor status was shown to be positive in 32 patients $(53.3 \%)$ and negative in 28 patients $(46.6 \%)$.

Table I Clinical Response Rate (RECIST Criteria) ${ }^{15}$

\begin{tabular}{|l|l|l|}
\hline Clinical Response & Frequency & Percent \\
\hline Complete Response & 16 & $26.6 \%$ \\
Partial Response & 30 & $50 \%$ \\
No Response & 8 & $13.3 \%$ \\
Progressive Disease & 6 & $10 \%$ \\
Total & 60 & $100 \%$ \\
\hline
\end{tabular}


Table 2 Pre-NACT T-Stage vs Post-NACT T-Stage

\begin{tabular}{|c|c|c|c|c|c|c|c|}
\hline & & \multicolumn{5}{|c|}{ Post Chemotherapy Tumor Stage } & \multirow[t]{2}{*}{ Total } \\
\hline & & TO & TI & T2 & T3 & T4 & \\
\hline \multirow[t]{3}{*}{ Pre-Chemotherapy Tumor Stage } & $\mathrm{T} 2$ & $\begin{array}{l}2 \\
3.3 \%\end{array}$ & $\begin{array}{l}0 \\
0.0 \%\end{array}$ & $\begin{array}{l}2 \\
3.3 \%\end{array}$ & $\begin{array}{l}0 \\
0.0 \%\end{array}$ & $\begin{array}{l}0 \\
0.0 \%\end{array}$ & $\begin{array}{l}4 \\
6.6 \%\end{array}$ \\
\hline & $\mathrm{T} 3$ & $\begin{array}{l}12 \\
20 \%\end{array}$ & $\begin{array}{l}5 \\
8.3 \%\end{array}$ & $\begin{array}{l}3 \\
5 \%\end{array}$ & $\begin{array}{l}4 \\
6.6 \%\end{array}$ & $\begin{array}{l}0 \\
0 \%\end{array}$ & $\begin{array}{l}24 \\
40.0 \%\end{array}$ \\
\hline & $\mathrm{T} 4$ & $\begin{array}{l}2 \\
3.3 \%\end{array}$ & $\begin{array}{l}10 \\
16.6 \%\end{array}$ & $\begin{array}{l}8 \\
13.3 \%\end{array}$ & $\begin{array}{l}4 \\
6.6 \%\end{array}$ & $\begin{array}{l}8 \\
13.3 \%\end{array}$ & $\begin{array}{l}32 \\
53.3 \%\end{array}$ \\
\hline Total & & $\begin{array}{l}16 \\
26.7 \%\end{array}$ & $\begin{array}{l}15 \\
25 \%\end{array}$ & $\begin{array}{l}13 \\
21.6 \%\end{array}$ & $\begin{array}{l}8 \\
13.3 \%\end{array}$ & $\begin{array}{l}8 \\
13.3 \%\end{array}$ & $\begin{array}{l}60 \\
100.0 \%\end{array}$ \\
\hline
\end{tabular}

Note: $P$-value $<0.05$.

According to Table 1, among the 60 patients 16 patients $(26.6 \%)$ had clinical complete remission (cCR), 30 patients $(50 \%)$ had partial remission, eight patients (13.3\%) had stable disease, and six patients (10\%) had progressive disease.

According to Table 2, post chemotherapy 16 (26.7\%) patients had complete remission (T0). Amongst the 32 (53.3\%) patients with pre-chemotherapy $\mathrm{T} 4$ disease, only eight (13.3\%) patients remained in T4 stage after chemotherapy. This shows a statistically significant reduction of $\mathrm{T}$ stage after chemotherapy $(P<0.05)$. T3 disease also responded significantly well to chemotherapy $(40 \%$ reduced to $13 \%$ ).

According to Table 3, clinical examination of axilla showed at the pre-chemotherapy stage, only eight (13.3\%) patients were in N0 stage. But, after NACT, there were 40 (66.7\%) patients with N0 disease. Hence, 32 (53.3\%)

Table 3 Pre-NACT Nodal Stage vs Post-NACT Nodal Stage

\begin{tabular}{|c|c|c|c|c|c|}
\hline & & \multicolumn{3}{|c|}{$\begin{array}{l}\text { Post- } \\
\text { Chemotherapy } \\
\text { Nodal Stage }\end{array}$} & \multirow[t]{2}{*}{ Total } \\
\hline & & No & NI & N2 & \\
\hline \multirow[t]{3}{*}{$\begin{array}{l}\text { Pre-Chemotherapy Nodal } \\
\text { Stage }\end{array}$} & No & $\begin{array}{l}8 \\
13.3 \%\end{array}$ & $\begin{array}{l}0 \\
0.0 \%\end{array}$ & $\begin{array}{l}0 \\
0.0 \%\end{array}$ & $\begin{array}{l}8 \\
13.3 \%\end{array}$ \\
\hline & NI & $\begin{array}{l}26 \\
43.3 \%\end{array}$ & $\begin{array}{l}14 \\
23.3 \%\end{array}$ & $\begin{array}{l}0 \\
0.0 \%\end{array}$ & $\begin{array}{l}40 \\
66.7 \%\end{array}$ \\
\hline & N2 & $\begin{array}{l}6 \\
10.0 \%\end{array}$ & $\begin{array}{l}2 \\
3.3 \%\end{array}$ & $\begin{array}{l}4 \\
6.7 \%\end{array}$ & $\begin{array}{l}12 \\
20.0 \%\end{array}$ \\
\hline \multicolumn{2}{|l|}{ Total } & $\begin{array}{l}40 \\
66.7 \%\end{array}$ & $\begin{array}{l}16 \\
26.7 \%\end{array}$ & $\begin{array}{l}4 \\
6.7 \%\end{array}$ & $\begin{array}{l}60 \\
100.0 \%\end{array}$ \\
\hline
\end{tabular}

Note: $P$-value $<0.05$. patients had a complete nodal response after chemotherapy. In addition to this, N2 stage disease was in $12(20 \%)$ patients (pre-chemotherapy), which reduced to four $(6.7 \%)$ patients after chemotherapy. This is statistically significant, with $P<0.05$. Comparatively, N1 disease also responded well with chemotherapy $(66.7 \%$ reduced to $26.7 \%)$.

According to Table 4, after NACT the response rate was good in those aged over 50 years, with a $P$-value $<0.05$. The NACT response rate was better in the post-menopausal group than in the premenopausal group, with a $P$-value $<0.05$. ER positive patients had a better clinical response rate than ER negative patients for NACT $(P$-value $<0.05)$. But there was no statistical difference in PR status and HER2-neu status in view of response rate after NACT $(P=0.385$ and $P=0.309)$. According to tumor grade, complete and partial response were better in low grade (1 and 2) tumors than high grade tumors (3), but it was not statistically significant $(P=0.143)$. While comparing the response rate to the tumor histology, invasive ductal CA has a significant response over other types $(P<0.05)$.

While analyzing the number of molecular subtypes of our cases there were 19 (31.6\%) Luminal A cases and 22 (36.6\%) luminal B cases, nine (15\%) triple negative cases, and $10(16 \%)$ HER 2 cases were identified.

According to Table 5, complete response was $45 \%$ in Luminal $\mathrm{B}$, and it is statistically significant $(P<0.05)$. But partial response is high $(P$-value $>0.05)$ in Luminal A cases (68.5\%).

If we combined both partial and complete response to chemotherapy, clinical response is good in luminal A (90\%) compared to luminal B (77\%). In TNBC, total clinical response is $78 \%$. While comparing complete 
Table 4 Post-NACT Response Rate Compared with Age, Menopausal State, ER, PR Her2neu, Tumor Grade, and Tumor Histology (Percentage within Group)

\begin{tabular}{|c|c|c|c|c|c|c|}
\hline & & $\begin{array}{l}\text { Complete } \\
\text { Response }\end{array}$ & $\begin{array}{l}\text { Partial } \\
\text { Response }\end{array}$ & Stable & Progressive & Total \\
\hline $\begin{array}{l}\text { Age } \\
(P<0.05)\end{array}$ & $\begin{array}{l}<50 \\
51 \text { and above }\end{array}$ & $\begin{array}{l}\text { I }(2.7 \%) \\
\text { I5 (62.5\%) }\end{array}$ & $\begin{array}{l}23(63.8 \%) \\
7(29 \%)\end{array}$ & $\begin{array}{l}6(16.6 \%) \\
\text { I (4\%) }\end{array}$ & $\begin{array}{l}6(16.6 \%) \\
I(4 \%)\end{array}$ & $\begin{array}{l}36 \\
24\end{array}$ \\
\hline $\begin{array}{l}\text { Menopausal state } \\
(P<0.05)\end{array}$ & $\begin{array}{l}\text { Pre- menopausal } \\
\text { Post- menopausal }\end{array}$ & $\begin{array}{l}4(16 \%) \\
12(34.2 \%)\end{array}$ & $\begin{array}{l}10(4 \%) \\
20(57 \%)\end{array}$ & $\begin{array}{l}5(2 \%) \\
3(8.5 \%)\end{array}$ & $\begin{array}{l}6(24 \%) \\
0(0 \%)\end{array}$ & $\begin{array}{l}25 \\
35\end{array}$ \\
\hline $\begin{array}{l}\text { ER status } \\
(P<0.05)\end{array}$ & $\begin{array}{l}\text { Positive } \\
\text { Negative }\end{array}$ & $\begin{array}{l}14(38.8 \%) \\
2(8.3 \%)\end{array}$ & $\begin{array}{l}20(55.5 \%) \\
10(41.6 \%)\end{array}$ & $\begin{array}{l}2(5.5 \%) \\
6(25 \%)\end{array}$ & $\begin{array}{l}0(0 \%) \\
6(25 \%)\end{array}$ & $\begin{array}{l}36 \\
24\end{array}$ \\
\hline $\begin{array}{l}\text { PR status } \\
(P=0.385)\end{array}$ & $\begin{array}{l}\text { Positive } \\
\text { Negative }\end{array}$ & $\begin{array}{l}10(32.2 \%) \\
6(20.6 \%)\end{array}$ & $\begin{array}{l}16(51.6 \%) \\
14(48.2 \%)\end{array}$ & $\begin{array}{l}3(9.6 \%) \\
5(17.2 \%)\end{array}$ & $\begin{array}{l}2(6.4 \%) \\
4(13.7 \%)\end{array}$ & $\begin{array}{l}31 \\
29\end{array}$ \\
\hline $\begin{array}{l}\text { Her2 -neu } \\
(P=0.309)\end{array}$ & $\begin{array}{l}\text { Positive } \\
\text { Negative }\end{array}$ & $\begin{array}{l}10(31.2 \%) \\
6(21.4 \%)\end{array}$ & $\begin{array}{l}17(53 \%) \\
13(46.4 \%)\end{array}$ & $\begin{array}{l}3(9.3 \%) \\
5(17.8 \%)\end{array}$ & $\begin{array}{l}2(6.2 \%) \\
4(14.2 \%)\end{array}$ & $\begin{array}{l}32 \\
28\end{array}$ \\
\hline $\begin{array}{l}\text { Grade } \\
(P=0.143)\end{array}$ & $\begin{array}{l}1 \text { and } 2 \\
3\end{array}$ & $\begin{array}{l}6(28.5 \%) \\
10(25.6 \%)\end{array}$ & $\begin{array}{l}\text { II (52\%) } \\
\text { I9 48.7\%) }\end{array}$ & $\begin{array}{l}3(14.2 \%) \\
5(12.8 \%)\end{array}$ & $\begin{array}{l}\text { I (4.7\%) } \\
5(12.8 \%)\end{array}$ & $\begin{array}{l}21 \\
39\end{array}$ \\
\hline $\begin{array}{l}\text { Histology } \\
(P<0.05)\end{array}$ & $\begin{array}{l}\text { Invasive ductal CA } \\
\text { Invasive lobular CA } \\
\text { Others and mixed }\end{array}$ & $\begin{array}{l}14(32.5 \%) \\
0(0 \%) \\
2(25 \%)\end{array}$ & $\begin{array}{l}22(51 \%) \\
5(55.5 \%) \\
3(37.5 \%)\end{array}$ & $\begin{array}{l}5(11.5 \%) \\
1(11 \%) \\
2(25 \%)\end{array}$ & $\begin{array}{l}2(4 \%) \\
3(33.3 \%) \\
I(12.5 \%)\end{array}$ & $\begin{array}{l}43 \\
9 \\
8\end{array}$ \\
\hline
\end{tabular}

pathological response (pCR) in this sub-group shows $22.2 \%$ of triple negative patients and $15.7 \%$ of luminal $\mathrm{A}$ patients had good response, which is not statistically significant $(P>0.05)$

Following NACT, 46 (76.6\%) patients underwent modified radical mastectomy surgery. All patients had axillary lymph node dissection (ALND). The other 14 patient continued their cycles of chemotherapy.

Among the operated cases eight patients (13.3\%) attained pCR. Although 16 patients $(26.6 \%)$ had complete clinical response (cCR), eight patients had residual disease in pathological specimens. At follow-up we found 5 year survival of these eight pCR patients was $100 \%$.

\section{Discussion}

Usage of NACT in LABC is very effective. In our study, the overall clinical response rate was $76.6 \%$ (complete + partial). In patients who achieved complete clinical response, residual tumor might still persist histologically. ${ }^{16-18}$ In our study, 16 patients (26.6\%) had cCR. Eight of them (13.3\%) had pCR, and the other eight (13.3\%) had residual disease histologically.

While comparing with another study, complete clinical response in our study (26.6\%) was comparable with Alvarado et al, ${ }^{19}$ which showed a cCR of $12 \%$, and Garbhi olfa et al, ${ }^{20}$ which showed a cCR of $14 \%$. The partial response rate in our study was $50 \%$. In Alvarado et al and Garbhi et al it was $28 \%$ and $49 \%$, respectively. pCR was $13.3 \%$ in our study, while it was $8 \%$ and $7 \%$ in Alvarado et al and Garbhi et al, respectively.

In Garbhi et al, the clinical response rate was assessed by univariate analysis: $63 \%$ in ER-positive tumors, $84 \%$ in ER-negative, 59\% in PR-positive, 62\% in PR-negative, $64 \%$ in HER2-positive, and $62 \%$ in HER 2 negative. These results were comparable to our study. In our study group the clinical response rates by each factor were as follows: 94\% in ER-positive tumors, 50\% in ER-negative, $83.8 \%$ in PR-positive, $68.8 \%$ in PR-negative, $84.2 \%$ in HER2-positive, and $87.8 \%$ in HER2-negative after three cycles of chemotherapy. 
Table 5 Clinical and Pathological Response in Molecular Sub-types

\begin{tabular}{|c|c|c|c|c|c|}
\hline & $\begin{array}{l}\text { Luminal A } \\
\text { (19) } 31.6 \%\end{array}$ & $\begin{array}{l}\text { Luminal B } \\
\text { (22) } 36.6 \%\end{array}$ & $\begin{array}{l}\text { TNBC } \\
\text { (9) } 15 \%\end{array}$ & $\begin{array}{l}\text { HER2 } \\
(10) 16 \%\end{array}$ & $P$-value \\
\hline Complete response (16) & $4(2 \mid .1 \%)$ & $10(45.5 \%)$ & $2(22.2 \%)$ & 0 & $\begin{array}{l}0.046 \\
(<0.05)\end{array}$ \\
\hline Partial response $(30)$ & $13(68.4 \%)$ & 7 (31.6\%) & $5(55.6 \%)$ & $5(50 \%)$ & $\begin{array}{l}0.133 \\
(>0.05)\end{array}$ \\
\hline Total response & 17 (90\%) & 17 (77\%) & 7 (78\%) & $5(50 \%)$ & $\begin{array}{l}0.126 \\
(>0.05)\end{array}$ \\
\hline Static disease (8) & $2(10.5 \%)$ & $3(13.6 \%)$ & 0 & $3(30 \%)$ & $\begin{array}{l}0.270 \\
(>0.05)\end{array}$ \\
\hline Progressive disease (6) & 0 & $2(9.1 \%)$ & $2(22.2 \%)$ & $2(20 \%)$ & $\begin{array}{l}0.192 \\
(>0.05)\end{array}$ \\
\hline Pathological response (8) & $3(15.7 \%)$ & $3(13.6 \%)$ & $2(22.2 \%)$ & 0 & $\begin{array}{l}0.324 \\
(>0.05)\end{array}$ \\
\hline
\end{tabular}

Del Prete et $\mathrm{al}^{21}$ shows good pathological responses of ER positive tumors, which is similar to our study.

In our study there was no significant difference in response rate in PR receptor status or Her2-neu status. In Miglietta et al, ${ }^{22}$ a good response was seen with Her2-neu over-expressed tumors. Resende et $\mathrm{al}^{23}$ showed no relationship with HER2-neu status of the patients. In our study the post-menopausal group and those aged above 51 had a better clinical response $(P<0.05)$ than those who were pre-menopausal and those aged below 50 years. Resende et al $^{23}$ shows no relationship with menopausal state. Del Prete et $\mathrm{al}^{21}$ showed good pathological response in premenopausal patients.

In our study, there is no statistically significant difference in grade of the tumor and clinical response. Overall clinical response was $80.5 \%$ in low grade (1 and 2) and $74.3 \%$ in high grade tumors. In contrast, Awad et al showed better responses in rapidly proliferating tumors with a higher grade. ${ }^{24}$ Resende et $\mathrm{al}^{23}$ also showed good response in high grade tumors.

While comparing clinical response and histological types, our study shows a more statistically significant clinical response in invasive ductal carcinoma than other types $(P<0.05)$. Similarly, Beresford et $\mathrm{al}^{25}$ reported a highly significant clinical response in patients with invasive ductal carcinoma. In addition to this, Alawad ${ }^{24}$ also showed 72 out of 76 patients diagnosed as invasive ductal carcinoma achieved a clinical response (complete or partial) to NACT. In Alawad, no lobular carcinomas had a complete pathological response to NACT. From this we can understand that histological type in breast carcinoma may play an important role in predicting the degree of clinical response to NACT.
While comparing this study based on molecular subtypes, Luminal B tumor had a complete clinical response (45\%), but total clinical response was better in Luminal A (90\%) tumors than Luminal B (only 77\%). This shows hormone positive, HER negative tumors will have good clinical response to NACT. Luminal A and Her2 patients had no progressive disease when compared to other groups. In addition to this, triple negative patients had a higher total clinical response in $78 \%$ of patients.

Pathological response is more valuable than clinical response, since it shows the histology proof for response. The pathologic complete response (pCR) after NACT is probably most predictive with respect to long-term treatment outcomes. ${ }^{26}$

The triple negative tumor is basically ER/PR negative, and evidence suggests that the negative hormone receptor status is one of the strongest predictive markers associated with the higher likelihood of pCR to NACT. ${ }^{27,28}$ In our study, triple negative patients had a good pathological response $(22.2 \%)$ followed by luminal $\mathrm{A}$ patients $(15.7 \%)$. In Kim et $\mathrm{al}^{29}{ }^{29}$ the cPR rate was high in triple negative patients $(21.1 \%)$, which is comparable to our study. In their study triple negative and Her 2 were more sensitive to NACT.

Incorporation of Trastuzumab with neoadjuvant chemotherapeutics is a promising alternative for the HER2 subtype. ${ }^{30}$ Phung et $\mathrm{al}^{31}$ shows neoadjuvant treatment with trastuzumab and chemotherapy combined in patients with HER2 positive breast cancer yielded a pathological complete response rate of $64.1 \%$.

In our study, due to logistic reasons, Trastuzumab was not given as NACT, and it was given only in the adjuvant 
setting. If we add it as a neo-adjuvant regimen it might improve the response rate in HER2 cases.

\section{Conclusion}

The preoperative chemotherapy (NACT) downstages the primary tumors and axillary metastasis in patients with LABC to operable tumors. The anthracycline-based chemotherapy along with Taxol gives good clinical and pathological responses in locally advanced breast CA. Though clinical response varies in tumor sub-types, pathological response is good in triple negative and Luminal A patients. Comparison of molecular sub-types with chemotherapy response is a better way to find out the predictors of response to chemotherapy. Adding Trastuzumab in NACT would improve the response rate in Her2 cases. Further studies with a larger number of cases are needed to come to the conclusion for predictors in molecular sub-types for NACT.

\section{Ethics Approval}

This study was approved by the Institutional Research Ethics Committee of Sri Ramachandra Medical University. It was conducted in accordance with the Declaration of Helsinki.

\section{Funding}

There was no funding from any organization or institute.

\section{Disclosure}

The authors report no conflicts of interest for this work.

\section{References}

1. Olivotto IA, Chua B, Allan SJ, et al. Long-term survival of patients with supraclavicular metastases at diagnosis of breast cancer. $J$ Clin Oncol. 2003;21:851-854. doi:10.1200/JCO.2003.11.105

2. Brito RA, Valero V, Buzdar AU, et al. Long-term results of combined modality therapy for locally advanced breast cancer with ipsilateral supraclavicular metastasis: the University of Texas M.D. Anderson Cancer Center experience. J Clin Oncol. 2001;19:628-633. doi:10. 1200/JCO.2001.19.3.628

3. Singletary SE, Allred C, Ahsley P, et al. Revision of the American Joint Committee on Cancer staging system for breast cancer. J Clin Oncol. 2002;20:3628-3636. doi:10.1200/JCO.2002.02.026

4. Kolscienly S, Tubiana M, Le MG, et al. Breast cancer: relationship between the size of the primary tumor and the probability of metastatic dissemination. Br J Cancer. 1984;49:709-715. doi:10.1038/bjc.1984. 112

5. Waljee JF, Newman LA. Surg Clin N Am. 2007;87:399-415. doi:10.1016/j.suc.2007.02.004

6. Swain SM, Sorace RA, Bagley CS, et al. NACT in the combined modality approach of LABC. Cancer Res. 1987;47:3889-3894.

7. Carter CL, Allen C, Hensen DE. Relation of Tumor size, lymph node station and survival in 24, 740 breast cancer cases. Cancer. 1989;63:181-187.
8. Valagassa $\mathrm{P}$, Zumbettu M, Bigma $\mathrm{P}$, et al. T3b-T4 breast cancer factors affecting results in combined modality treatment. Clin Exp Metastasis. 1983;1::191-202. doi:10.1007/BF00121498

9. Semiglazov VF, Topuzov EE, Bavli JL, et al. Primary chemotherapy \& Radiotherapy compared with primary radiotherapy above in Stage IIb - iIIa breast carcinoma. Ann Oncol. 1994;5:591-595. doi:10.10 93/oxfordjournals.annonc.a058929

10. VanderHge JA, Vendevelde CJ, Julien JP, et al. Preoperative chemotherapy in primary operable breast cancer results from the European organization for research and treatment of cancer trial 10902. J Clin Oncol. 2001;19::4224-4237. doi:10.1200/JCO.2001. 19.22.4224

11. Kayal S, Biswajit D, Cyriac SL, et al. Comparison of neoadjuvant chemotherapy (NACT) with 5-fluorouracil, epirubicin (100mg), cyclophosphamide (FEC100) followed by docetaxel (D) (75mg) versus adriamycin and cyclophosphamide (AC) followed by docetaxel (100mg) in locally advanced breast cancer (LABC): a randomized clinical study. J Clin Oncol. 33(15_suppl). doi:10.1200/jco.2015. 33.15_suppl.e12002

12. Buzdar A, Suman VJ, Meric-Bernstam F, et al. ACOSOG Z1041 (Alliance): definitive analysis of randomized neoadjuvant trial comparing FEC followed by paclitaxel plus trastuzumab $(\mathrm{FEC} \rightarrow \mathrm{P}+\mathrm{T})$ with paclitaxel plus trastuzumab followed by FEC plus trastuzumab $(\mathrm{P}+\mathrm{T} \rightarrow \mathrm{FEC}+\mathrm{T})$ in HER2+ operable breast ca. J Clin Oncol. 2013;31(15_suppl):502. doi:10.1200/jco.2013.31.15_suppl.502

13. Kaufmann $\bar{M}$, Hortobagyi GN, Goldhirsch A, et al. von Minckwitz G: recommendations from an international expert panel on the use of neoadjuvant (primary) systemic treatment of operable breast cancer: an update. J Clin Oncol. 2006;24:1940-1949. doi:10.1200/JCO.2005.02.6187

14. Sorlie T, Tibshirani R, Parker J, et al. Repeated observation of breast tumor subtypes in independent gene expression data sets. Proc Natl Acad Sci USA. 2003;100:8418-8423. doi:10.1073/pnas.0932692100

15. Eisenhauer EA, Therasse P, Bogaerts J, et al. New response evaluation criteria in solid tumours: revised RECIST guideline (version 1.1). Eur J Cancer. 2009;45(2):228-247

16. Fernandez-Sanchez M, Gamboa-Dominguez A, Uribe N, et al. Clinical and pathological predictors of the response to neoadjuvant anthracycline chemotherapy in locally advanced breast cancer. Med Oncol. 2006;23(2):171-183. doi:10.1385/MO:23:2:171

17. Schwartz G. Neoadjuvant induction chemotherapy. Minerva Ginecol. 2005;57(3):327-348.

18. Charfare H, Limongelli S, Purushotham AD. Neoadjuvant chemotherapy in breast cancer. Br J Surg. 2005;92(1):14-23. doi:10. $1002 /$ bjs. 4840

19. Alvarado-Cabrero I, Alderete-Vazquez G, Quintal- Ramirez M, Patino M, Ruiz E. Incidence of pathologic complete response in women treated with preoperative chemotherapy for locally advanced breast cancer: cor- relation of histology, hormone receptor status, Her2/Neu, and gross pathologic findings. Ann Diagn Pathol. 2009;13(3):151-157.

20. Olfaa G, Amelb T, Rima C, et al. Clinical and pathological response to neoadjuvant anthracy- cline based chemotherapy in women with breast cancer. World J Oncol. 2010;1(4):167-17211.

21. Del Prete S, et al. Clinical and pathological factors predictive of response to neoadjuvant chemotherapy in breast cancer: a single center experience. Oncol Lett. 2019;18(4):3873-3879. doi:10.3892/ ol.2019.10729

22. Miglietta L, et al. Clinical and pathological response to primary chemotherapy in patients with locally advanced breast cancer grouped according to hormonal receptors, Her2 status, grading and Ki. Anticancer Res. 2009;29(5):1621-1625.

23. Resende U, Cabello C, Ramalho SOB, et al. Prognostic assessment of breast carcinoma submitted to neoadjuvant chemotherapy with pathological non-complete response. BMC Cancer. 2019;19:601. doi:10. 1186/s12885-019-5812-0 
24. Alawad AAM. Evaluation of clinical and pathological response after two cycles of neoadjuvant chemotherapy on sudanese patients with locally advanced breast cancer. Ethiop J Health Sci. 2014;24 (1):15-20. doi:10.4314/ejhs.v24i1.2

25. Beresford MJ, Stott D, Makris A. Assessment of clinical response after two cycles of primary chemotherapy in breast cancer. Breast Cancer Res Treat. 2008;109:5. doi:10.1007/s10549-007-9644-2

26. Rastogi P, Anderson SJ, Bear HD, et al. Preoperative chemotherapy: updates of national surgical adjuvant breast and bowel project protocols B-18 and B-27. J Clin Oncol. 2008;26:778-785. doi:10.1200/ JCO.2007.15.0235

27. Maur M, Guarneri V, Frassoldati A, Conte PF. Primary systemic therapy in operable breast cancer: clinical data and biological fall-out. Ann Oncol. 2006;17:158-164. doi:10.1093/annonc/mdj 973

28. Burcombe RJ, Makris A, Richman PI, et al. Evaluation of ER, PgR, HER-2 and Ki-67 as predictors of response to neoadjuvant anthracycline chemotherapy for operable breast cancer. $\mathrm{Br} J$ Cancer. 2005;92:147-155. doi:10.1038/sj.bjc.6602256
29. Kim. SI, Sohn. J, Koo. JS, Park SH, Park BW. Molecular subtypes and tumor response to neoadjuvant chemotherapy in patients with locally advanced breast cancer-clinical translational research. Oncology. 2010;79:324-330. doi:10.1159/000322192

30. Gianni L, Eiermann W, Semiglazov V, et al. Neoadjuvant chemotherapy with trastuzumab followed by adjuvant trastuzumab versus neoadjuvant chemotherapy alone, in patients with HER2-positive locally advanced breast cancer (the NOAH trial): a randomised controlled superiority trial with a parallel HER2-negative cohort. Lancet. 2010;375:377-384.

31. Phung HT, Nguyen HT, Van Nguyen T, Van Nguyen T, Thi Dinh LA, Van Nguyen C. Pathological complete response with neoadjuvant trastuzumab combined with Chemotherapy in HER2 positive breast cancer: a single institution retrospective analysis from vietnam. Breast Cancer. 2020;12:117-122.

\section{Publish your work in this journal}

Breast Cancer - Targets and Therapy is an international, peer-reviewed open access journal focusing on breast cancer research, identification of therapeutic targets and the optimal use of preventative and integrated treatment interventions to achieve improved outcomes, enhanced survival and quality of life for the cancer patient.
The manuscript management system is completely online and includes a very quick and fair peer-review system, which is all easy to use. Visit http://www.dovepress.com/testimonials.php to read real quotes from published authors. 